\title{
Endometrial mesenchymal stem/stromal cell modulation of T cell proliferation
}

\author{
Xiaoqing Yang 1,2,*, Meivita Devianti,*, Yuan $\mathrm{H}^{1, \text { Yang}^{3}}$, Yih Rue Ong ${ }^{1}$, Ker Sin Tan, \\ Shanti Gurung ${ }^{4}$, Jean L Tan ${ }^{1}$, Dandan Zhu ${ }^{1}$, Rebecca Lim ${ }^{1,5}$, Caroline E Gargett ${ }^{1,5}$ and \\ James A Deane ${ }^{1,5}$ \\ ${ }^{1}$ The Ritchie Centre, Hudson Institute of Medical Research, Clayton, Victoria, Australia, ${ }^{2}$ Department of Obstetrics \\ and Gynecology, Affiliated Hospital of Nantong University, NanTong, Jiangsu, China, ${ }^{3}$ Centre for Inflammatory \\ Diseases, Department of Medicine, Monash University, Monash Medical Centre, Clayton, Victoria, Australia, ${ }^{4}$ Centre \\ for Reproductive Health, Hudson Institute of Medical Research, Clayton, Victoria, Australia and ${ }^{5}$ Department of \\ Obstetrics and Gynaecology, Monash University, Clayton, Victoria, Australia \\ Correspondence should be addressed to J A Deane; Email: james.deane@hudson.org.au
}

*(X Yang and M Devianti contributed equally to this work)

\begin{abstract}
Perivascular mesenchymal stem/stromal cells can be isolated from the human endometrium using the surface marker SUSD2 and are being investigated for use in tissue repair. Mesenchymal stem/stromal cells from other tissues modulate T cell responses via mechanisms including interleukin-10, prostaglandin E2, TGF- $\beta 1$ and regulatory T cells. Animal studies demonstrate that endometrial mesenchymal stem/stromal cells can also modify immune responses to implanted mesh, but the mechanism/s they employ have not been explored. We examined the immunomodulatory properties of human endometrial mesenchymal stem/stromal cells on lymphocyte proliferation using mouse splenocyte cultures. Endometrial mesenchymal stem/stromal cells inhibited mitogen-induced lymphocyte proliferation in vitro in a dose-dependent manner. Inhibition of lymphocyte proliferation was not affected by blocking the mouse interleukin-10 receptor or inhibiting prostaglandin production. Endometrial mesenchymal stem/stromal cells continued to restrain lymphocyte proliferation in the presence of an inhibitor of TGF- $\beta$ receptors, despite a reduction in regulatory T cells. Thus, the in vitro inhibition of mitogen-induced lymphocyte proliferation by endometrial mesenchymal stem/stromal cells occurs by a mechanism distinct from the interleukin-10, prostaglandin E2, TGF- $\beta 1$ and regulatory T cell-mediated mechanisms employed by MSC from other tissues. eMSCs were shown to produce interleukin-17A and Dickkopf-1 which may contribute to their immunomodulatory properties. In contrast to MSC from other sources, systemic administration of endometrial mesenchymal stem/stromal cells did not inhibit swelling in a T cell-mediated model of skin inflammation. We conclude that, while endometrial mesenchymal stem/stromal cells can modify immune responses, their immunomodulatory repertoire may not be sufficient to restrain some T cell-mediated inflammatory events.

Reproduction (2019) 157 43-52
\end{abstract}

\section{Introduction}

Mesenchymal stem/stromal cells (MSCs) are plastic adherent, colony-forming cells with adipogenic, chondrogenic and osteogenic differentiation potential (Phinney \& Prockop 2007). They have a characteristic combination of cell-surface markers including CD29, CD44, CD73 and CD105, and lack the haematopoietic markers CD34 and CD45 (Dominici et al. 2006, Lv et al. 2014). MSC were originally isolated from bone marrow, but have more recently been identified in many other tissues including the human endometrium (Schwab \& Gargett 2007, Crisan et al. 2008, Gargett et al. 2009).

An important feature of MSC is their ability to reduce inflammation or modify immune responses resulting in reduced fibrosis (De Miguel et al. 2012). These properties have been harnessed to treat disease and injury. The mechanisms by which MSCs modulate immune responses include producing anti-inflammatory factors such as interleukin-10 (IL-10), prostaglandin E2 (PGE2), transforming growth factor- $\beta 1$ (TGF- $\beta 1$ ) and hepatocyte growth factor (HGF) (Soleymaninejadian et al. 2012). These factors and contact-mediated mechanisms suppress the proliferation and activity of $\mathrm{T}$ cells, B-cells, natural killer cells and dendritic cells and promote regulatory $\mathrm{T}$ cell (Treg) differentiation (Augello et al. 2005, English et al. 2009, Zhang et al. 2009, Ghannam et al. 2010, Duffy et al. 2011, Gebler et al. 2012). 
The W5C5 mouse monoclonal antibody recognising the human SUSD2 surface protein (Sivasubramaniyan et al. 2013) identifies an oestrogen receptor- $\alpha$ (ER- $\alpha$ )negative population of perivascular MSC in the human endometrium (eMSC) with colony-forming and multilineage differentiation properties (Masuda et al. 2012). SUSD2 ${ }^{+}$eMSCs are distinct from endometrial fibroblasts, which are sometimes also referred to as MSC, but have a more limited differentiation capacity, are not clonogenic and express ER- $\alpha$ (Gargett et al. 2016).

SUSD2 ${ }^{+}$eMSC can be isolated from an endometrial biopsy obtained in an anaesthetic-free, office-based procedure and are easily expanded in culture (Ulrich et al. 2013). In a rat fascial defect model, eMSC delivered on a mesh scaffold reduced immune cell infiltration, skewed macrophages toward a reparative M2 phenotype and reduced the stiffness of tissue repair (Ulrich et al. 2014). In a mouse model of subcutaneous mesh implantation, eMSC reduced inflammatory mediators and promoted M2 polarisation of macrophages (Darzi et al. 2018). Thus, eMSCs are readily accessible and have many potential therapeutic applications (Ulrich et al. 2013); however, the immunomodulatory mediators they employ have not been defined. Here, we use in vitro and in vivo assays to investigate the immunomodulatory mechanisms of human SUSD2 ${ }^{+}$eMSC.

\section{Materials and methods}

\section{Human endometrial tissue collection}

Human endometrium was obtained from six women with regular menstrual cycles undergoing endometrial biopsy or a hysterectomy, who had not taken exogenous hormones for 3 months prior to tissue collection. Informed written consent was obtained from each patient and the study protocol was approved by Monash Health (09270B) and Monash University (CF/10/2080 - 2010001150) Human Research Ethics Committees. Samples were collected in Hepes-buffered Dulbecco Modified Eagle Medium/Hams F-12 (DMEM/F-12; Invitrogen) with antibiotics and 5\% fetal bovine serum (FBS) (CSL, Parkville, Australia), stored at $4^{\circ} \mathrm{C}$ and processed within $18 \mathrm{~h}$.

\section{Endometrial MSC purification and expansion}

Endometrial tissue was diced and dissociated into a singlecell suspension by digestion in $\mathrm{Ca}^{2+}$ and $\mathrm{Mg}^{2+}$-free phosphate buffered saline (PBS) (Gibco/ThermoFisher Scientific) containing $50 \mu \mathrm{g} / \mathrm{mL}$ collagenase type I (Worthington Biochemical Corporation, Freehold, NJ, USA) and $40 \mu \mathrm{g} /$ $\mathrm{mL}$ deoxyribonuclease type I (Roche Diagnostics) for $60 \mathrm{~min}$ on a rotating MacsMix (Miltenyi Biotec) at $37^{\circ} \mathrm{C}$ in a $5 \% \mathrm{CO}_{2}$ humidified incubator (Ulrich et al. 2014). Cells were filtered through a $40 \mu \mathrm{m}$ sieve (Merck Millipore) to separate dissociated stromal cells from collagenase-resistant epithelial structures and undigested fragments. Ficoll-Paque
(GE Healthcare Biosciences) was used to separate stromal single-cell suspensions from red blood cells.

Dissociated endometrial stromal cells were incubated with phycoerythrin (PE)-conjugated SUSD2 antibody (50 ng/ $10^{7}$ cells, Biolegend, San Diego, CA, USA) for $20 \mathrm{~min}$ at $4^{\circ} \mathrm{C}$ in $0.5 \%$ FBS in PBS $\left(100 \mu \mathrm{L} / 10^{7}\right.$ cells) (Bead Medium), washed with Bead Medium and incubated with anti-PE magneticactivated cell sorting (MACS) Microbeads (Miltenyi Biotec) for $20 \mathrm{~min}$ at $4^{\circ} \mathrm{C}$ in Bead Medium $\left(80 \mu \mathrm{L} / 10^{7}\right.$ cells). Cells were washed with Bead Medium and applied to a Miltenyi Column (Miltenyi Biotec) in a magnetic field to purify magnetically labelled SUSD2 ${ }^{+}$eMSC.

Purified SUSD2 ${ }^{+}$cells were seeded at $1.25 \times 10^{5}$ cells/ $\mathrm{cm}^{2}$ on fibronectin-coated culture flasks in stromal medium, containing DMEM/F-12 medium, 10\% FBS, 1\% glutamine (Invitrogen) and $0.2 \%$ primocin antibiotic (InvivoGen, San Diego, CA, USA), with $10 \mathrm{ng} / \mathrm{mL}$ basic fibroblast growth factor. Medium was changed every two days and cells were grown until 70-90\% confluent. TrypLE Express (Life Technologies/ ThermoFisher Scientific) containing a trypsin substitute was used to harvest cells at each passage and eMSCs were used in assays at passage $1-3$.

\section{Immunofluorescence microscopy}

P1 SUSD2 ${ }^{+}$endometrial cells were grown to confluence in stromal medium on round plastic coverslips in six-well plates, fixed for $10 \mathrm{~min}$ with $4 \%$ paraformaldehyde, washed with PBS and then $0.2 \%$ Triton X-100 in PBS, blocked using serum-free protein blocking reagent (Prod \#X0909 - Dako, North Sydney NSW, Australia), incubated for $1 \mathrm{~h}$ at $25^{\circ} \mathrm{C}$ with PE-conjugated SUSD2 antibody (1:100) or a PE-conjugated Mouse IgG-1 (Invitrogen/ThermoFisher Scientific) isotype control and then washed. Nuclei were stained with Hoechst 33258. Plastic coverslips and attached cells were mounted under a glass coverslip and examined using a Nikon C1 confocal microscope.

\section{Flow cytometry}

To assess whether MACS-purified eMSC maintained their identity when expanded in culture, $1 \times 10^{5} \mathrm{P} 2 \mathrm{SUSD}^{+}$cells in $100 \mu \mathrm{L}$ of $2 \%$ FBS in PBS (Flow Cytometry Buffer) were blocked with $5 \mu \mathrm{L}$ of mouse serum for $5 \mathrm{~min}$ on ice, washed in Flow Cytometry Buffer, incubated with PE-SUSD2 antibody or a PE-IgG1 isotype control at a 1:100 dilution for $20 \mathrm{~min}$ on ice, washed and analysed on a FACS Canto II flow cytometer with FACS Diva Software (BD Biosciences, Le Pont-deClaix, France).

\section{Mouse splenocytes}

Mouse splenocytes were obtained from spleens scavenged from adult C57BL/6] background mice or FoxP3-GFP mice euthanised for colony maintenance or training purposes. Mice were from breeding colonies or projects approved by a Monash Medical Centre Animal Ethics Committee. 


\section{$\left[{ }^{3} \mathrm{H}\right]$-thymidine lymphocyte proliferation assay}

Irradiated P1 eMSC (30Gy) were seeded into a flat-bottom 96-well plate in $200 \mu \mathrm{L}$ of stromal medium per well. Mouse splenocytes $\left(5 \times 10^{5}\right.$ cells/well) were plated into wells seeded with eMSC at eMSC:mouse splenocyte ratios spanning 1:3250 to $1: 10$. An IL-10 receptor blocking antibody specific for mouse (clone 1B1.3A, BioXCell, West Lebanon, NH, USA) $(25 \mu \mathrm{g} /$ $\mathrm{mL}$ ) (O'Farrell et al. 1998) or a Rat IgG1 $(25 \mu \mathrm{g} / \mathrm{mL})$ isotype control, were added to cocultures of eMSC and splenocytes at a $1: 10$ ratio.

Concanavalin A (ConA) (Sigma-Aldrich) at $0.1 \mu \mathrm{g} / \mu \mathrm{L}$ was used to induce lymphocyte proliferation and cocultures were incubated for $48 \mathrm{~h}$ in $5 \% \mathrm{CO}_{2}$ at $37^{\circ} \mathrm{C}$. Two mCi $\left[{ }^{3} \mathrm{H}\right]$-thymidine was added $16-18 \mathrm{~h}$ prior to culture termination. This assay was performed in triplicate, harvested and proliferation was gauged by measuring radioactivity incorporation using a liquid scintillation analyzer. Assays with clear ConA-mediated splenocyte proliferation in the absence of eMSC (cpm>three times unstimulated control) were included in analyses.

\section{Measuring lymphocyte proliferation using a CFSE dilution assay}

$1 \times 10^{5}$ P2-3 eMSC were plated into a flat-bottom 24-well plate, cultured for $24 \mathrm{~h}$ and a cell count was performed on a representative well. Mouse splenocytes were labelled with $5 \mu \mathrm{M}$ carboxyfluorescein succinimidyl ester (CFSE) in PBS for $5 \mathrm{~min}$ at room temperature and washed three times with PBS $+5 \%$ FBS and added to eMSC at a 1:5 ratio of eMSC to splenocytes. ConA at $0.5 \mu \mathrm{g} / \mu \mathrm{L}$ was used to induce lymphocyte proliferation. Indomethacin (Sigma-Aldrich) was used at $30 \mu \mathrm{M}$ or $60 \mu \mathrm{M}$ to inhibit prostaglandin synthesis. A83-01 (Tocris Bioscience) was used at $1 \mu \mathrm{M}$ to inhibit TGF- $\beta$ signalling via the ALK4, ALK5 and ALK7 receptors.

Cocultures were incubated for $72 \mathrm{~h}$ in $5 \% \mathrm{CO}_{2}$ at $37^{\circ} \mathrm{C}$. Cultures were harvested and $\mathrm{CD}^{+} \mathrm{T}$ cells analysed for CFSE on a BD LSR II flow cytometer using anti-CD4-APC at 1:200 (clone GK1.5, eBioscience) and 4',6-diamidino-2phenylindole (DAPI) staining to exclude dead cells. Peaks of CFSE labelling corresponding to undivided cells with the highest CFSE intensity, and weaker peaks corresponding to divided cells were identified in $\mathrm{CD}^{+}$CFSE peaks. The proliferation modelling feature of Flow) 10.3 software (Flow)o LLC, Ashland, Oregon) was used to calculate expansion index (fold-expansion of original population) and replication index (fold-expansion of responding cells) (Roederer 2011).

\section{Monitoring regulatory $T$ cells}

eMSCs were plated with splenocytes isolated from mice with GFP $^{+}$Tregs (FoxP3-GFP) (Fontenot et al. 2005) at a 1:5 ratio of eMSC to splenocytes and cultured with $0.5 \mu \mathrm{g} / \mu \mathrm{L}$ ConA for $72 \mathrm{~h}$ plus/minus A83-01 as described for the CFSE dilution assay. Tregs were identified as a $\mathrm{CD}^{+}{ }^{+} \mathrm{FoxP} 3-\mathrm{GFP}^{+}$population by flow cytometry using CD4-APC at 1:200 (clone GK1.5, eBioscience) and DAPI staining to exclude dead cells.

\section{eMSC cytokine, chemokine and growth factor profile}

Supernatant was collected from CFSE dilution assays at $72 \mathrm{~h}$, centrifuged to remove debris and stored at $-20^{\circ} \mathrm{C}$. $500 \mu \mathrm{L}$ of supernatant from two independent eMSC/splenocyte cocultures plus or minus ConA was used on a membranebased antibody array (Human XL Cytokine Array Kit, Cat \#ARY022B, R\&D Systems) according to the manufacturer's instructions. The antibodies used in this array recognise human proteins with little or no cross reactivity to mouse. Results were collected using a ChemiDoc XRS+ imaging system (BIO RAD). FIJI software (Schindelin et al. 2012) was used to subtract background and measure integrated pixel density.

\section{Mouse contact sensitivity model of T cell-mediated skin inflammation}

Mouse experiments were approved in advance by a Monash Medical Centre Animal Ethics Committee and conducted in accordance with the National Health and Medical Research Council of Australia guidelines for the use of animals in research. Mice were sensitised by the application of $50 \mu \mathrm{L} 5 \%$ oxazolone (Sigma-Aldrich) in an acetone/olive oil vehicle $(4: 1)$ to a shaved patch on the back. Five days after sensitisation $1 \times 10^{6}$ eMSC in PBS were injected via the tail vein. Six days after sensitisation $20 \mu \mathrm{L}$ of $0.5 \%$ oxazolone in vehicle was applied to the right ear, and vehicle applied to the left ear as a control. Ear thickness was measured using a micrometre.

\section{Statistical analysis}

GraphPad Prism was used for data analysis and plotting graphs. $\left[{ }^{3} \mathrm{H}\right]$-thymidine incorporation lymphocyte proliferation data frequently did not pass the Shapiro-Wilk normality test and was analysed using Friedman's test and Dunn's multiple comparison test to identify statistically significant differences between groups. CFSE dilution and ear swelling data passed the Shapiro-Wilk normality test and was analysed using oneway ANOVA and Tukey's multiple comparisons test.

\section{Results}

\section{Perivascular eMSC isolated using the W5C5 antibody retain a SUSD2 $2^{+}$phenotype after expansion in culture}

The W5C5 antibody recognised SUSD2+ perivascular cells in the human endometrium (Fig. 1A). Magnetic bead sorting of dissociated endometrium with the W5C5 antibody yielded cells that grew vigorously to confluence for all samples used. After 1-2 passages in culture most cells continued to express SUSD2 (>60\%) as judged by immunofluorescence microscopy (Fig. 1B) and flow cytometry (Fig. 1C and D). A broad range of labelling intensities were observed indicating variable levels of SUSD2 expression in cultured eMSC (Fig. 1B and D) as described previously (Masuda et al. 2012). Isotype controls verified the specificity of immunofluorescence 

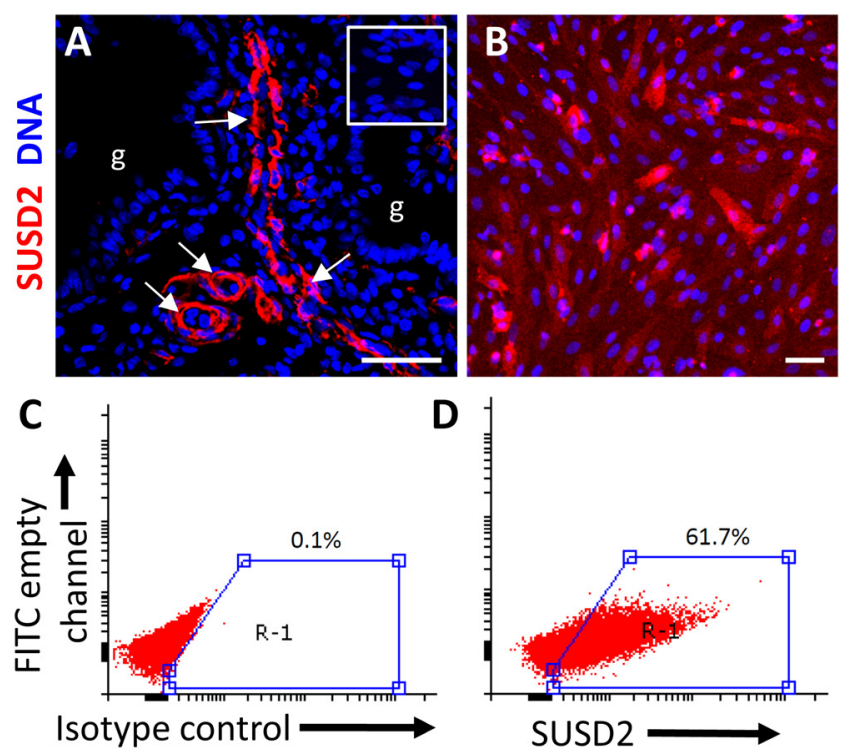

Figure 1 Purification and expansion of human perivascular SUSD2+ endometrial MSC. (A) The W5C5 antibody recognises SUSD2 ${ }^{+}$ perivascular cells (red, arrows) in the human endometrium. g, gland. Inset shows an isotype control to demonstrate antibody specificity. (B, C and D) SUSD2 antibody-purified and cultured eMSC retain SUSD2 expression as detected by immunostaining (B, red), or by flow cytometry (D). An isotype control (C) demonstrates antibody specificity. Nuclei are stained with Hoechst in A and B. Scale bars $=50 \mu \mathrm{m}$.

(Fig. 1A) and flow cytometric (Fig. 1C) detection of SUSD2 ${ }^{+}$cells using the W5C5 antibody.

\section{eMSC inhibit lymphocyte proliferation in a dose- dependent manner independent of IL-10 signalling}

The ability of human eMSC to supress lymphocyte proliferation was tested by coculture with ConAstimulated mouse splenocytes. As shown in Fig. 2A, eMSC suppressed lymphocyte proliferation at a high eMSC:lymphocyte ratio of 1:10, but suppression diminished in a dose-dependent manner as the relative number of eMSC was reduced. Baseline lymphocyte proliferation in the absence of ConA was not affected by eMSC at the ratios tested (Fig. 2A).

We investigated whether the anti-inflammatory cytokine IL-10 was responsible for inhibiting ConAmediated lymphocyte proliferation by blocking the mouse IL-10 receptor on splenocytes with an antibody. Blocking the IL-10 receptor did not prevent the inhibitory effect of eMSC on lymphocyte proliferation (Fig. 2A). A lymphocyte proliferation dataset was compiled from five patient-derived eMSC samples using a ratio of cpm for ConA+ vs ConA- to control for inter-assay and sample variation (Fig. 2B). Dose-dependent inhibition of ConAmediated lymphocyte proliferation was a consistent feature of eMSC that did not require splenocyte IL-10 receptor function.
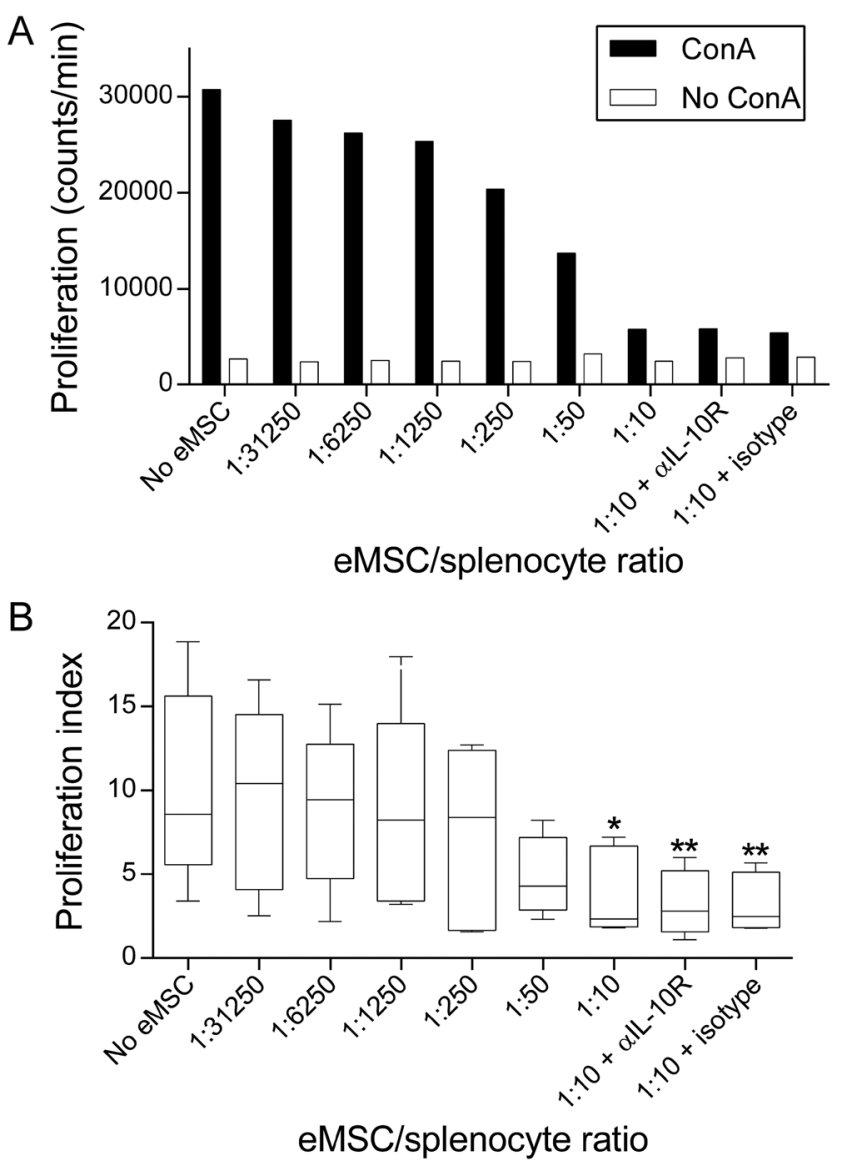

Figure 2 Dose-dependent inhibition of lymphocyte proliferation in vitro by endometrial MSC. (A) Inhibition of lymphocyte proliferation by eMSC from a representative patient-derived culture. Black columns show ConA-mediated lymphocyte proliferation measured by incorporation of $\left[{ }^{3} \mathrm{H}\right]$-thymidine. Basal levels of proliferation in the absence of ConA are shown by white columns. $\alpha$ IL-10R indicates the inclusion of an IL-10 receptor-blocking antibody and isotype indicates a control antibody. (B) Proliferation index $\left(\mathrm{ConA}^{+} \mathrm{cpm} /\right.$ ConA- $\mathrm{A}^{-} \mathrm{cpm}$ ) measured from five patient-derived eMSC cultures. Boxes show median and interquartile range; whiskers show minimum to maximum. ${ }^{*} P<0.05$ and ${ }^{*} P P<0.01$ using Friedman's test and Dunn's post hoc test.

\section{eMSC inhibition of $C D 4^{+} T$ cell proliferation does not require PGE synthesis or TGF- $\beta$ signalling}

A CFSE dilution assay was optimised to measure $\mathrm{CD} 4^{+} \mathrm{T}$ cell proliferation history in splenocyte/eMSC cocultures over $72 \mathrm{~h}$ and allow proliferation modelling. In this assay, CFSE-loaded splenocytes produced only small $T$ cell colonies in the absence of ConA, while ConA induced the growth of larger colonies (Fig. 3). The inclusion of eMSC at a ratio of 1:5 inhibited ConA-induced colony growth in a manner that was unaffected by the inhibitor of prostaglandin synthesis indomethacin, but colony growth was restored by the TGF- $\beta$ receptor inhibitor A83-01 (Fig. 3).

Flow cytometry for $\mathrm{CD}^{+} \mathrm{T}$ cells in cultures without ConA detected a single bright peak for CFSE 

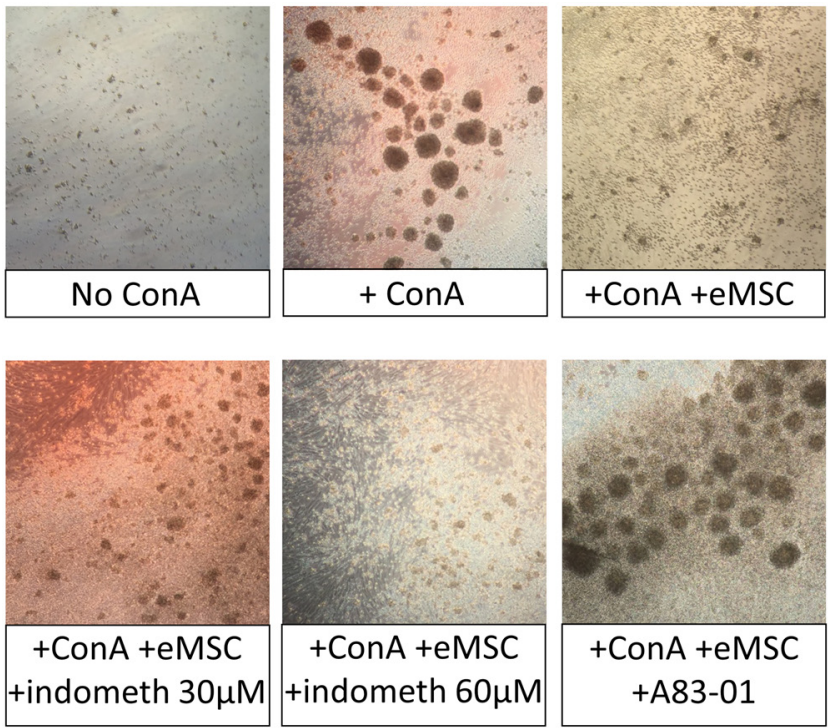

Figure 3 Lymphocyte colonies from cultured mouse splenocytes and the effects of eMSC, inhibition of prostaglandin synthesis and TGF- $\beta$ signalling. Indomethacin was used to inhibit prostaglandin synthesis and A83-01 to inhibit TGF- $\beta$ signalling. Mouse splenocytes cultured for $72 \mathrm{~h}$ without ConA (No ConA); with ConA (+ConA); with ConA and eMSC (+ConA +eMSC); with ConA, eMSC and indomethacin (+ConA +eMSC + indometh); with ConA, eMSC and A83-01 (+ConA $+\mathrm{eMSC}+\mathrm{A} 83-01)$. Images are representative of $n=7$ for No ConA and + ConA; $n=5$ for + Con $\mathrm{A}+\mathrm{eMSC}$ ) and +Con $\mathrm{A}+$ indometh $30 \mu \mathrm{M}$; $n=4$ for + ConA + eMSC +indometh $60 \mu \mathrm{M}$, and $n=3$ for + ConA $+\mathrm{eMSC}+\mathrm{A} 83-01$.

corresponding to non-divided $\mathrm{CD}^{+} \mathrm{T}$ cells (Fig. 4A). Cultures stimulated with ConA had multiple additional weaker CFSE peaks corresponding to $\mathrm{CD}^{+} \mathrm{T}$ cells that had undergone one or more rounds of division (Fig. 4A). The inclusion of eMSC increased the relative size of the peak corresponding to non-divided lymphocytes (Fig. 4A). The effect of eMSC was not altered by indomethacin, but was reversed by A83-01 (Fig. 4B).

The relative magnitude of CFSE peaks corresponding to non-divided and dividing cells was used to model proliferation (Fig. 5). Control cultures lacking eMSC were used to examine the potential for eMSCindependent effects of indomethacin and A83-01 on ConA-mediated lymphocyte proliferation (Fig. 5). eMSC reduced the extent of ConA-induced lymphocyte proliferation as measured by the expansion index (foldexpansion of original population) and the replication index (fold-expansion of responding cells) for $\mathrm{CD}^{+}$ $\mathrm{T}$ cells (Fig. 5). The addition of indomethacin at two concentrations $(30 \mu \mathrm{M}$ and $60 \mu \mathrm{M})$ failed to reverse the inhibition of $\mathrm{CD}^{+} \mathrm{T}$ cell proliferation by eMSC, but A83-01 restored $\mathrm{CD}^{+} \mathrm{T}$ cell proliferation to levels that were not significantly different to control cultures lacking eMSC (Fig. 5). Controls lacking eMSC indicated that indomethacin did not significantly change ConAmediated lymphocyte proliferation as measured by expansion or replication indices. A83-01 in the absence
A
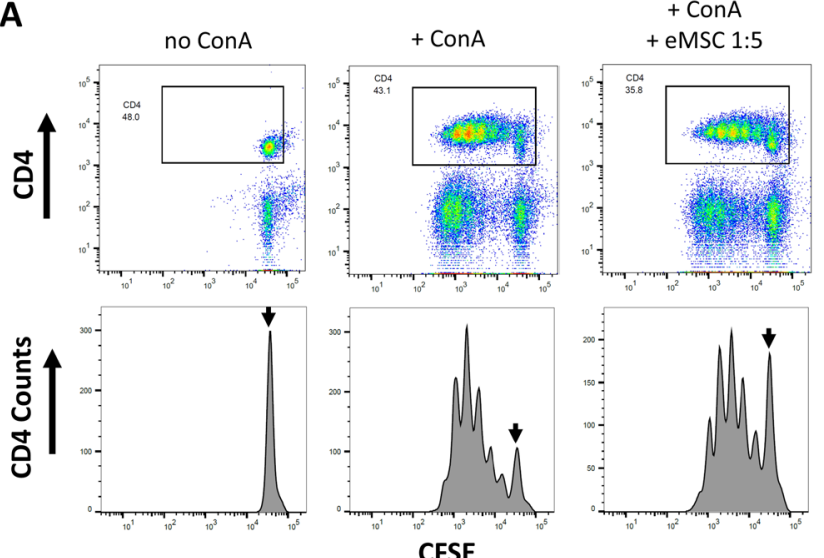

B

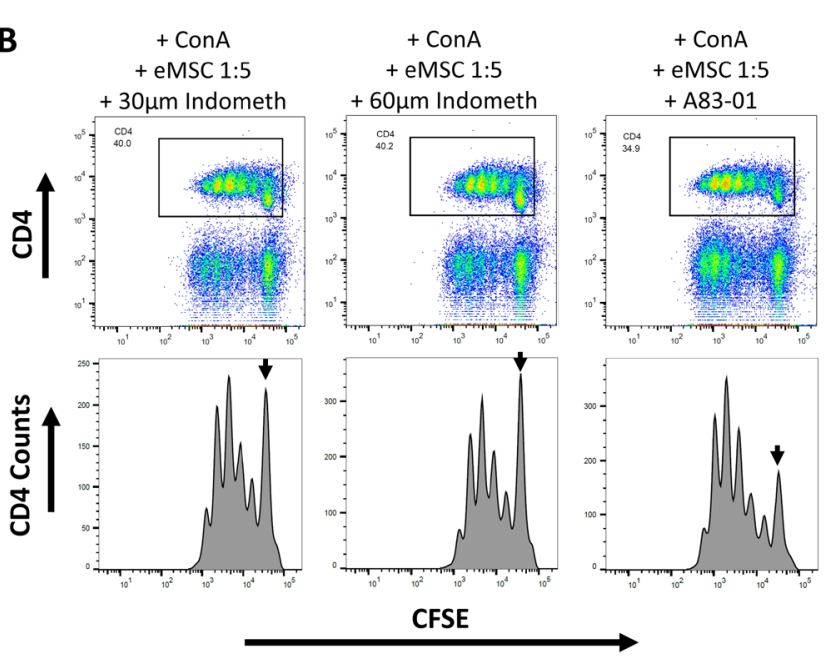

Figure $4 \mathrm{CD}^{+}{ }^{+} \mathrm{T}$ cell proliferation and the effects of eMSC measured by CFSE dilution. (A and B) A gate for CFSE-labelled CD4+ ${ }^{+}$cells (rectangle in dot plot panels) was used to generate histograms of CD4 ${ }^{+}$counts vs CFSE intensity (lower panels). Arrows in histograms show peaks of undivided cells. (A) Splenocyte cultures without ConA (no ConA), with ConA $(+\operatorname{Con} \mathrm{A})$, or with ConA and eMSC $(+\operatorname{Con} \mathrm{A}$ +eMSC 1:5). (B) Splenocyte/eMSC cocultures with ConA plus indomethacin or A83-01. Plots are representative of $n=7$ for No ConA and + ConA; $n=5$ for + ConA +eMSC 1:5 and +ConA +eMSC $1: 5+30 \mu \mathrm{M}$ indometh; $n=4$ for + ConA + eMSC $1: 5+60 \mu \mathrm{M}$ indomethacin, and $n=3$ for + ConA +eMSC 1:5 +A83-01.

of eMSC resulted in significantly higher lymphocyte proliferation than eMSC plus A83-01 (Fig. 5), indicating that eMSC restrain lymphocyte proliferation even when TGF- $\beta$ signalling is inhibited.

\section{Blocking TGF- $\beta$ signalling reduces regulatory $T$ cell abundance}

A CD4 ${ }^{+}$FoxP3-GFP ${ }^{+}$population of Tregs and a $\mathrm{CD}^{+}$FoxP3-GFP- ${ }^{-}$population of conventional $\mathrm{T}$ cells were identified in splenocyte cultures by flow cytometry (Fig. 6A). Treg abundance as a percentage of total CD4 ${ }^{+}$ $\mathrm{T}$ cells was significantly higher in eMSC/splenocyte cultures relative to A83-01-treated splenocytes without 


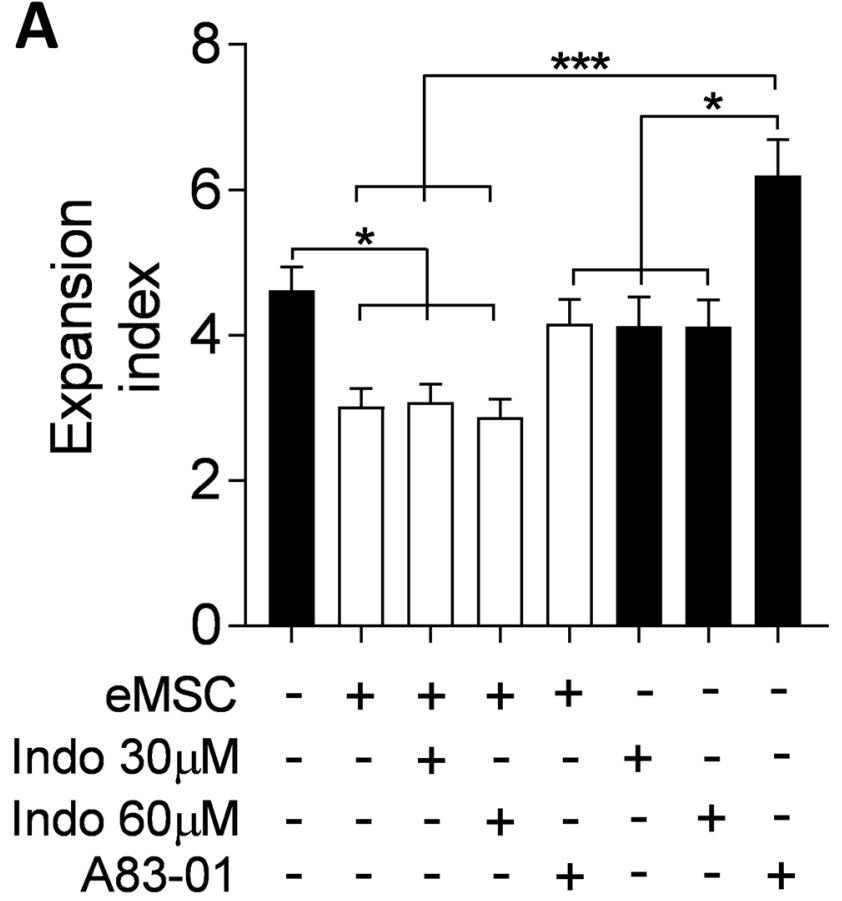

B

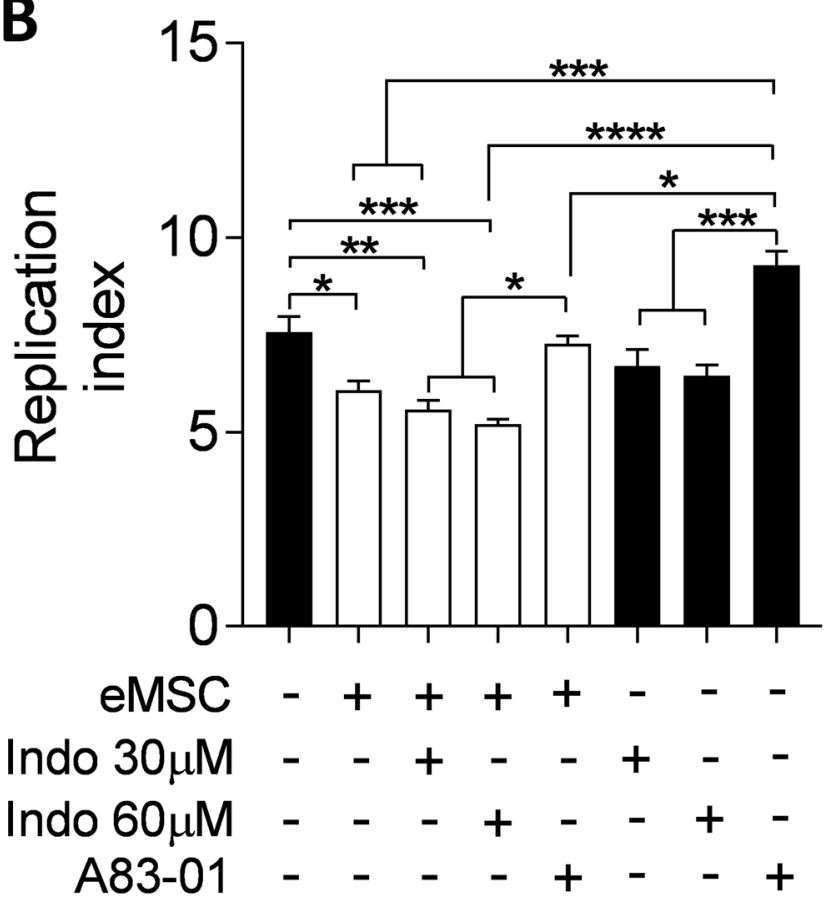

Figure 5 Quantification of $\mathrm{CD} 4^{+} \mathrm{T}$ cell proliferation. $\mathrm{CD} 4^{+} \mathrm{T}$ cell expansion index (A) and replication index (B) were calculated from CFSE dilution experiments. Data are shown as average \pm S.E.M. and open white columns show cocultures containing eMSC, 30 $\mu \mathrm{M}$ indomethacin. $n=7$ for untreated control without eMSC; $n=5$ for eMSC, eMSC $+30 \mu \mathrm{M}$ indomethacin; $n=4$ for eMSC $+60 \mu \mathrm{M}$ indomethacin, eMSC +A83-01, $60 \mu \mathrm{M}$ indomethacin; $n=3$ for A83-01. ${ }^{*} P<0.05,{ }^{* *} P<0.01,{ }^{* * *} P<0.005,{ }^{* * * *} P<0.001$ using one-way ANOVA and Tukey's multiple comparisons test.
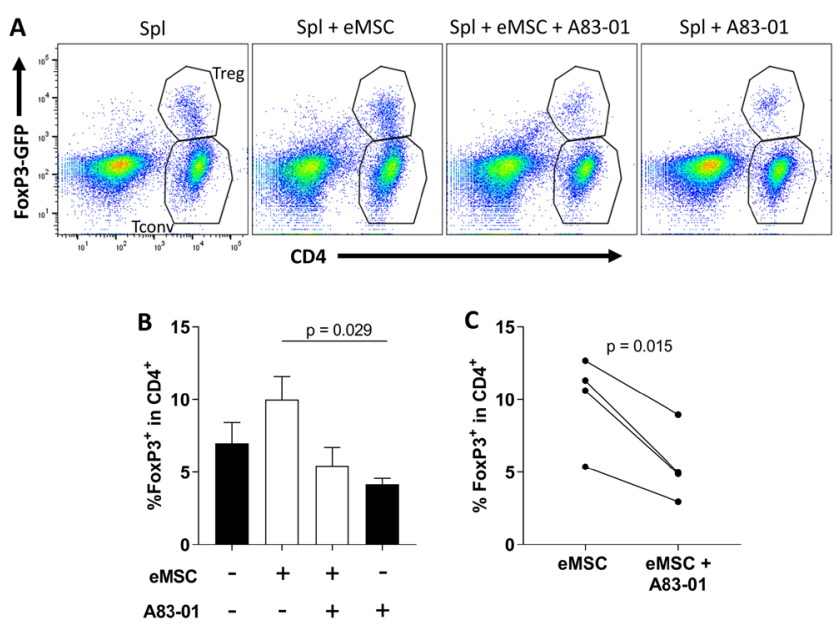

Figure 6 Quantification of regulatory T cells in splenocyte cultures. (A) $\mathrm{CD}^{+}$FoxP3-GFP+ ${ }^{+}$regulatory T cells (Treg) and CD4+FoxP3-GFPconventional T cells (Tconv) were identified by flow cytometry. Spl, splenocytes; eMSC, endometrial mesenchymal stem cells. Plots shown are representative of $n=4$ for each group. (B) The relative abundance of $\mathrm{CD}^{+}{ }^{+} \mathrm{FoxP} 3^{+}$Tregs is expressed as a percentage of the total $\mathrm{CD}^{+}$population including conventional T cells. Data are shown as average \pm S.E.M. and open white columns show cocultures containing eMSC. $n=4$ for all groups. Data were analysed using one-way ANOVA and Tukey's multiple comparisons test. (C) eMSC vs eMSC +A83-01 analysed using a paired $t$ test.

eMSC (Fig. 6B). A83-01 reduced Treg abundance in eMSC/splenocyte cocultures compared with paired untreated cocultures (Fig. 6C).

\section{eMSC cytokine, chemokine and growth factor profile}

Secreted human products detected in the supernatant from two eMSC/mouse splenocyte cocultures are shown in Fig. 7. Factors produced were similar for both eMSC cocultures, with the exception of chitinase 3 -like 1 and IGFBP-2 that were prominent in supernatant from only one eMSC coculture (Fig. 7A and B). Factors detected readily for both eMSC cocultures were angiogenin, angiopoietin-1, Dickkopf-1 (Dkk-1), fibroblast growth factor-19 (FGF-19), growth/differentiation factor-15 (GDF-15), interleukin-8 (IL-8), interleukin-17A (IL-17A), monocyte chemoattractant protein-1 (MCP-1), stromal cell-derived factor $1 \alpha(\mathrm{SDF}-1 \alpha)$, serpin E1 and thrombospondin-1 (Fig. 7B). The anti-inflammatory/ immunomodulatory factors HGF and IL-10 were not readily detected (Fig. 7B). Stimulating mouse lymphocyte proliferation in cocultures using ConA did not change the profile of factors produced by eMSC (Fig. 7B).

\section{eMSCs do not reduce skin contact sensitivity}

Oxazolone challenge of sensitised mice resulted in ear reddening and swelling that peaked after $24 \mathrm{~h}$ (Fig. 8A and $B$ ). The course of swelling as measured by ear 
A
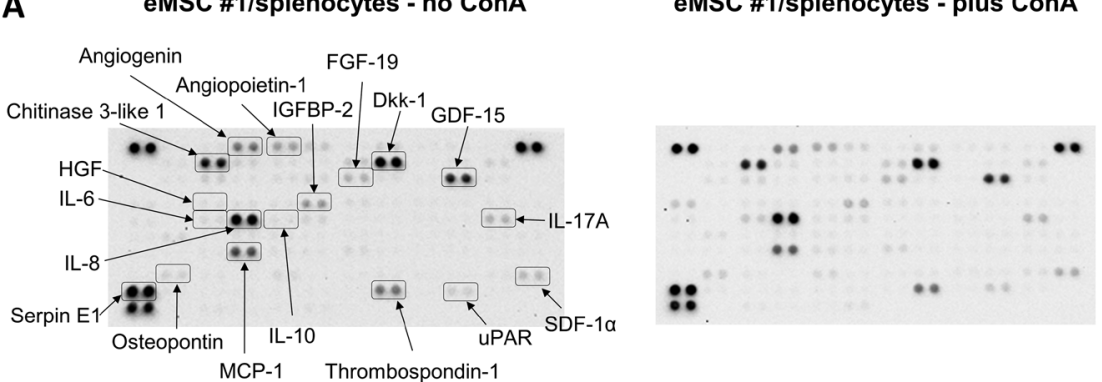

B

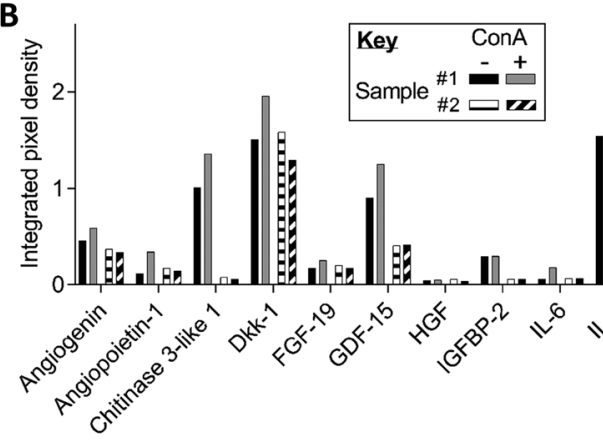

thickness was not significantly modified at 8,24 or $48 \mathrm{~h}$ in mice treated with intravenous eMSC $24 \mathrm{~h}$ prior to challenge relative to vehicle-treated controls (Fig. 8C).

\section{Discussion}

$\mathrm{SUSD}^{+}{ }^{+} \mathrm{eMSC}$ have therapeutic potential because they are easily obtained and purified, can be expanded in culture and modulate inflammatory responses (Masuda et al. 2012, Rajaraman et al. 2013, Ulrich et al. 2014, Darzi et al. 2018). Lymphocyte proliferation is an important part of most immune responses and the ability of MSC to supress lymphocyte proliferation is used as a measure of their immunosuppressive capacity. In this study, we show that eMSCs suppress lymphocyte proliferation induced by the mitogen ConA in a dosedependent manner as demonstrated for MSC from other tissues (Krampera et al. 2013). However, eMSC did not employ common immunomodulatory mechanisms described for MSC from other human tissues and were unable to restrain swelling in a mouse model of $\mathrm{T}$ cellmediated skin inflammation.

IL-10 can mediate the anti-proliferative effects of bone marrow MSC (Beyth et al. 2005, Gao et al. 2008, Yang et al. 2009) and mouse cells are receptive to human IL-10 (Moore et al. 1993). In our in vitro model, blocking the IL-10 receptor on splenocytes with a mouse-specific antibody did not reduce eMSC suppression of lymphocyte proliferation. Prostaglandin E2 is a common MSC-derived inhibitor of lymphocyte proliferation (Najar et al. 2010, Zafranskaya et al. 2013). Inhibition of prostaglandin synthesis with indomethacin failed to prevent eMSC-mediated inhibition of $\mathrm{CD}^{+}$ $\mathrm{T}$ cell proliferation. These results argue against a role for IL-10 and prostaglandins in the inhibition of T cell proliferation by eMSC in the in vitro context studied.

TGF- $\beta 1$ derived from bone marrow MSC restrains lymphocyte proliferation (Di Nicola et al. 2002). In our experiments inhibiting TGF- $\beta$ signalling with A8301 increased lymphocyte proliferation in splenocyte cultures containing eMSC. Taken in isolation, this result could be interpreted as an indication that MSCs inhibit lymphocyte proliferation via TGF- $\beta$ signalling. However, A83-01 also increased lymphocyte proliferation in control A83-01 treated cultures lacking eMSC, suggesting that a basal level of TGF- $\beta$ signalling restrains lymphocyte proliferation in ConA-stimulated splenocyte cultures. Lymphocyte proliferation in A8301 -treated cultures containing eMSC did not reach the elevated levels observed in A83-01 treated cultures lacking eMSC, indicating that eMSCs continue to inhibit lymphocyte proliferation via mechanisms independent of TGF- $\beta$ signalling. TGF- $\beta$ signalling promotes the differentiation of anti-inflammatory Tregs by TGF- $\beta 1$ via the ALK5 receptor and synergistic effects of Activin A via the ALK4 receptor (Chen et al. 2003, Huber et al. 2009). We confirmed that A83-01 reduces Treg abundance in both the presence and absence of eMSC. Tregs inhibit lymphocyte proliferation by multiple mechanisms (Schmidt et al. 2012). It is likely that reduced Treg differentiation in the presence of A83-01 accounts for observed increases in lymphocyte proliferation. This result also demonstrates that the anti-proliferative effect of eMSC is not linked to the abundance of Tregs. The concepts considered here are summarised in Fig. 9.

Potential factors involved in eMSC inhibition of lymphocyte proliferation were further explored by examining the cytokines, chemokines and growth 
A

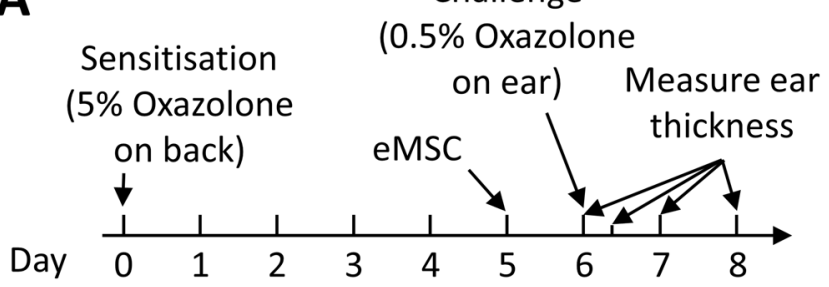

B

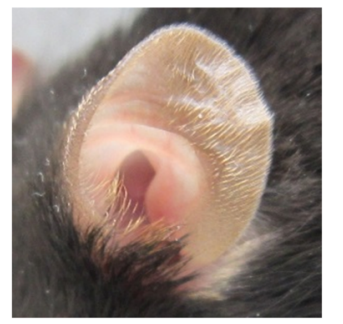

Vehicle

C

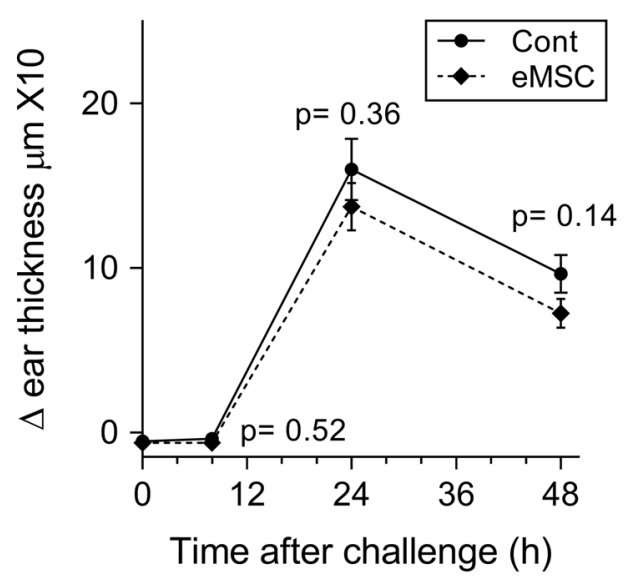

Figure 8 eMSC do not inhibit T cell-mediated ear inflammation. (A) A timeline of the mouse contact sensitivity model of ear swelling. (B) An uninflamed vehicle-challenged ear compared to an inflamed oxazolone-challenged ear. (C) Measurement of ear thickness difference between oxazolone and vehicle-treated ears. Data are shown as average \pm S.E.M. and were analysed using an unpaired $t$ test with $P$ value shown for control vs eMSC. $n=13$ for vehicle control and 11 for eMSC at $0-24 \mathrm{~h} . n=11$ for vehicle control and 8 for eMSC at $48 \mathrm{~h}$.

factors produced by eMSC cocultured with mouse splenocytes. IL-17A and Dkk-1 are the most likely candidates identified because they have previously been implicated in the ability of MSC to inhibit T cell proliferation (Sun et al. 2011, Han et al. 2014, Sivanathan et al. 2015). Thrombospondin-1 was also produced by eMSC may activate TGF- $\beta$ to promote Treg differentiation (Futagami et al. 2007). HGF is involved in the inhibition of lymphocyte proliferation by bone marrow MSC (Di Nicola et al. 2002), but its production by eMSC was minimal in the context studied. IL-10 is a notable MSC anti-inflammatory factor that was not readily detected. This is in keeping with our observation that blocking the IL-10 receptor did not reverse eMSC
A

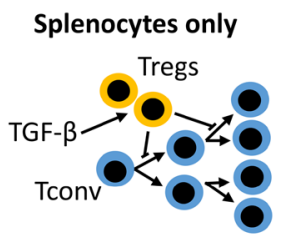

C Splenocytes + eMSC + A83-01

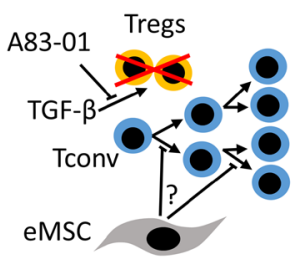

B Splenocytes + eMSC

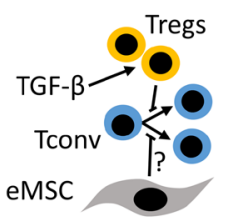

D Splenocytes + A83-01

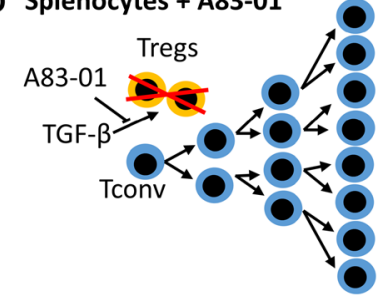

Figure 9 Summary of the effects of eMSC and TGF- $\beta$ signalling on lymphocyte proliferation. (A) TGF- $\beta$ promotes the differentiation of regulatory $T$ cells (Tregs) that inhibit T-lymphocyte (Tconv) proliferation. (B) eMSCs further inhibit lymphocyte proliferation via a mechanism independent of TGF- $\beta$ signalling. (C) A83-01 increases lymphocyte proliferation by reducing TGF- $\beta$ signalling-dependent Treg differentiation, but eMSCs continue to inhibit lymphocyte proliferation via a mechanism independent of TGF- $\beta$ signalling. (D) Maximum lymphocyte proliferation occurs in the absence of TGF- $\beta$ signalling-dependent Treg differentiation, and the absence of inhibition by eMSC.

inhibition of lymphocyte proliferation. Profiling also revealed that eMSCs produce immune cell chemoattractants (IL-8 and MCP-1), angiogenic (angiogenin and angiopoietin-1) and profibrotic (serpin E1) factors. Stimulating T cell expansion with ConA did not change the eMSC factors produced, indicating that the profile observed is a basal repertoire, rather than a response to actively expanding T cells. Further work is required to test the effects of eMSC-derived IL-17A and Dkk-1 on lymphocyte proliferation. Studies of MSC from other sources also suggest that indoleamine 2,3-dioxygenase warrants further investigation (Meisel et al. 2004, Soleymaninejadian et al. 2012). It will also be important to confirm that the $\mathrm{T}$ cell-directed immunomodulatory properties of human eMSC identified in mouse splenocyte assays apply to human T cells.

Mouse skin contact sensitivity models are commonly used to investigate $\mathrm{T}$ cell-mediated inflammation. These models involve an initial application of chemical sensitiser, followed by a challenge with the same chemical several days later to elicit a robust $T$ cellmediated inflammatory response featuring immune cell recruitment and swelling (Deane \& Hickey 2009, Deane et al. 2012). MSC from bone marrow (Chen et al. 2018), adipose tissue (Kikuchi et al. 2017) and gingiva (Su et al. 2011, Li et al. 2016) have the ability to inhibit ear swelling in contact sensitivity when delivered via and intravenous route. In contrast, eMSCs did not inhibit ear swelling in an oxazolone-induced model of contact sensitivity. eMSCs may be unable to suppress 
inflammation in this setting because they do not employ the $\mathrm{T}$ cell-directed immunomodulatory mechanisms used by other MSC types, particularly prostaglandin E2. This is consistent with observations that the phenotype and function of MSC varies greatly depending on tissue of origin (Le Blanc \& Davies 2018). Another pertinent difference may be the perivascular origin of eMSC used in our study, a feature that was not confirmed for the MSC used in previous studies of contact sensitivity. The molecular signature of perivascular MSC is different to those from a non-perivascular origin (Rohart et al. 2016) and may indicate functional differences. Cross species incompatibility has also been reported to limit the immunomodulatory properties of MSC in some instances (Lohan et al. 2018), a factor that may be relevant in the xenogeneic in vivo setting we examined.

We conclude that SUSD2 ${ }^{+}$eMSCs have a distinct immunomodulatory repertoire that lacks mechanisms commonly described for MSC from other tissues. The precise mechanism by which eMSC inhibit lymphocyte proliferation remains to be determined, although our analysis suggest IL-17A and Dkk-1 may be involved. Understanding the immunomodulatory repertoire of eMSC will inform the development of eMSC-based therapies and clarify the contribution of eMSC to the development of an endometrium that can support implantation and pregnancy.

\section{Declaration of interest}

The authors declare that there is no conflict of interest that could be perceived as prejudicing the impartiality of the research reported.

\section{Funding}

This study was funded by National Health and Medical Research Council (NHMRC) of Australia grants (1085235, C E G, J A D), 1081944 (C E G), NHMRC Senior Research Fellowship (1042298, C E G) and the Victorian Government Operational Infrastructure Support Scheme.

\section{Acknowledgements}

The authors acknowledge the assistance of Dr Courtney McDonald with proliferation assays, Dr Luke Larmour with interpreting pathology reports and patient data, Prof. Michael Hickey and Pamela Hall for providing FoxP3-GFP spleens and IL-10 receptor blocking antibody and the Monash Micro Imaging and Histology Facilities at the Hudson Institute of Medical Research. C E Gargett and J A Deane: equal senior authors.

\section{References}

Augello A, Tasso R, Negrini SM, Amateis A, Indiveri F, Cancedda R \& Pennesi G 2005 Bone marrow mesenchymal progenitor cells inhibit lymphocyte proliferation by activation of the programmed death 1 pathway. European Journal of Immunology 35 1482-1490. (https://doi. org/10.1002/eji.200425405)

Beyth S, Borovsky Z, Mevorach D, Liebergall M, Gazit Z, Aslan H, Galun E \& Rachmilewitz J 2005 Human mesenchymal stem cells alter antigenpresenting cell maturation and induce T-cell unresponsiveness. Blood 105 2214-2219. (https://doi.org/10.1182/blood-2004-07-2921)

Chen W, Jin W, Hardegen N, Lei KJ, Li L, Marinos N, McGrady G \& Wahl SM 2003 Conversion of peripheral CD4+CD25- naive T cells to CD4+CD25+ regulatory T cells by TGF-beta induction of transcription factor Foxp3. Journal of Experimental Medicine 198 1875-1886. (https:// doi.org/10.1084/jem.20030152)

Chen X, Liu Q, Huang W, Cai C, Xia W, Peng Y, Zheng S, Li G, Xu Y, Wang J et al. 2018 Stanniocalcin-2 contributes to mesenchymal stromal cells attenuating murine contact hypersensitivity mainly via reducing CD8(+) Tc1 cells. Cell Death and Disease 9 548. (https://doi.org/10.1038/ s41419-018-0614-x)

Crisan M, Yap S, Casteilla L, Chen CW, Corselli M, Park TS, Andriolo G, Sun B, Zheng B, Zhang L et al. 2008 A perivascular origin for mesenchymal stem cells in multiple human organs. Cell Stem Cell $\mathbf{3}$ 301-313. (https://doi.org/10.1016/j.stem.2008.07.003)

Darzi S, Deane JA, Nold CA, Edwards SE, Gough DJ, Mukherjee S, Gurung S, Tan KS, Vashi AV, Werkmeister JA et al. 2018 Endometrial mesenchymal stem/stromal cells modulate the macrophage response to implanted polyamide/gelatin composite mesh in immunocompromised and immunocompetent mice. Scientific Reports 86554 (https://doi. org/10.1038/s41598-018-24919-6)

De Miguel MP, Fuentes-Julian S, Blazquez-Martinez A, Pascual CY, Aller MA, Arias J \& Arnalich-Montiel F 2012 Immunosuppressive properties of mesenchymal stem cells: advances and applications. Current Molecular Medicine 12 574-591. (https://doi.org/10.2174/156652412800619950)

Deane JA \& Hickey MJ 2009 Molecular mechanisms of leukocyte trafficking in T-cell-mediated skin inflammation: insights from intravital imaging. Expert Reviews in Molecular Medicine 11 e25. (https://doi.org/10.1017/ S146239940900115X)

Deane JA, Abeynaike LD, Norman MU, Wee JL, Kitching AR, Kubes P \& Hickey MJ 2012 Endogenous regulatory T cells adhere in inflamed dermal vessels via ICAM-1: association with regulation of effector leukocyte adhesion. Journal of Immunology 188 2179-2188. (https:// doi.org/10.4049/jimmunol.1102752)

Di Nicola M, Carlo-Stella C, Magni M, Milanesi M, Longoni PD, Matteucci P, Grisanti S \& Gianni AM 2002 Human bone marrow stromal cells suppress T-lymphocyte proliferation induced by cellular or nonspecific mitogenic stimuli. Blood 99 3838-3843. (https://doi. org/10.1182/blood.V99.10.3838)

Dominici M, Le Blanc K, Mueller I, Slaper-Cortenbach I, Marini F, Krause D, Deans R, Keating A, Prockop D \& Horwitz E 2006 Minimal criteria for defining multipotent mesenchymal stromal cells. The International Society for Cellular Therapy position statement. Cytotherapy 8 315-317. (https://doi.org/10.1080/14653240600855905)

Duffy MM, Pindjakova J, Hanley SA, McCarthy C, Weidhofer GA, Sweeney EM, English K, Shaw G, Murphy JM, Barry FP et al. 2011 Mesenchymal stem cell inhibition of T-helper 17 cell-differentiation is triggered by cell-cell contact and mediated by prostaglandin E2 via the EP4 receptor. European Journal of Immunology 41 2840-2851. (https:// doi.org/10.1002/eji.201141499)

English K, Ryan JM, Tobin L, Murphy MJ, Barry FP \& Mahon BP 2009 Cell contact, prostaglandin $\mathrm{E}(2)$ and transforming growth factor beta 1 play non-redundant roles in human mesenchymal stem cell induction of CD4+CD25(High) forkhead box P3+ regulatory T cells. Clinical and Experimental Immunology 156 149-160. (https://doi.org/10.1111/ j.1365-2249.2009.03874.x)

Fontenot JD, Rasmussen JP, Williams LM, Dooley JL, Farr AG \& Rudensky AY 2005 Regulatory T cell lineage specification by the forkhead transcription factor foxp3. Immunity 22 329-341. (https://doi. org/10.1016/j.immuni.2005.01.016)

Futagami Y, Sugita S, Vega J, Ishida K, Takase H, Maruyama K, Aburatani H \& Mochizuki M 2007 Role of thrombospondin-1 in T cell response to ocular pigment epithelial cells. Journal of Immunology 178 6994-7005. (https://doi.org/10.4049/jimmunol.178.11.6994)

Gao K, Chen Y, Wei L, Li S, Jin X, Cong C, Yuan Y, Long D, Li Y, Cheng J et al. 2008 Inhibitory effect of mesenchymal stem cells on lymphocyte 
proliferation. Cell Biochemistry and Function 26 900-907. (https://doi. org/10.1002/cbf.1523)

Gargett CE, Schwab KE, Zillwood RM, Nguyen HP \& Wu D 2009 Isolation and culture of epithelial progenitors and mesenchymal stem cells from human endometrium. Biology of Reproduction 80 1136-1145. (https:// doi.org/10.1095/biolreprod.108.075226)

Gargett CE, Schwab KE \& Deane JA 2016 Endometrial stem/progenitor cells: the first 10 years. Human Reproduction Update 22 137-163.

Gebler A, Zabel O \& Seliger B 2012 The immunomodulatory capacity of mesenchymal stem cells. Trends in Molecular Medicine 18 128-134. (https://doi.org/10.1016/j.molmed.2011.10.004)

Ghannam S, Pene J, Moquet-Torcy G, Jorgensen C \& Yssel H 2010 Mesenchymal stem cells inhibit human Th17 cell differentiation and function and induce a T regulatory cell phenotype. Journal of Immunology 185 302-312. (https://doi.org/10.4049/jimmunol.0902007)

Han X, Yang Q, Lin L, Xu C, Zheng C, Chen X, Han Y, Li M, Cao W, Cao K et al. 2014 Interleukin-17 enhances immunosuppression by mesenchymal stem cells. Cell Death and Differentiation 21 1758-1768. (https://doi.org/10.1038/cdd.2014.85)

Huber S, Stahl FR, Schrader J, Luth S, Presser K, Carambia A, Flavell RA, Werner S, Blessing M, Herkel J et al. 2009 Activin a promotes the TGFbeta-induced conversion of CD4+CD25- T cells into Foxp3+ induced regulatory T cells. Journal of Immunology 182 4633-4640. (https://doi. org/10.4049/jimmunol.0803143)

Kikuchi S, Yanaba K, Nobeyama Y, Yabe S, Kiso M, Saeki H, Tada Y, Nakagawa H \& Okochi H 2017 Suppressive effects of mesenchymal stem cells in adipose tissue on allergic contact dermatitis. Annals of Dermatology 29 391-399. (https://doi.org/10.5021/ad.2017.29.4.391)

Krampera M, Galipeau J, Shi Y, Tarte K \& Sensebe L 2013 Immunological characterization of multipotent mesenchymal stromal cells the International Society for Cellular Therapy (ISCT) working proposal. Cytotherapy 15 1054-1061. (https://doi.org/10.1016/j. jcyt.2013.02.010)

Le Blanc K \& Davies LC 2018 MSCs-cells with many sides. Cytotherapy 20 273-278. (https://doi.org/10.1016/j.jcyt.2018.01.009)

Li P, Zhao Y \& Ge L 2016 Therapeutic effects of human gingiva-derived mesenchymal stromal cells on murine contact hypersensitivity via prostaglandin E2-EP3 signaling. Stem Cell Research and Therapy 7103. (https://doi.org/10.1186/s13287-016-0361-9)

Lohan P, Treacy O, Morcos M, Donohoe E, Y O'Donoghue, Ryan AE, Elliman SJ, Ritter T \& Griffin MD 2018 Interspecies incompatibilities limit the immunomodulatory effect of human mesenchymal stromal cells in the rat. Stem Cells 36 1210-1215. (https://doi.org/10.1002/stem.2840)

Lv FJ, Tuan RS, Cheung KM \& Leung VY 2014 Concise review: the surface markers and identity of human mesenchymal stem cells. Stem Cells $\mathbf{3 2}$ 1408-1419. (https://doi.org/10.1002/stem.1681)

Masuda H, Anwar SS, Buhring HJ, Rao JR \& Gargett CE 2012 A novel marker of human endometrial mesenchymal stem-like cells. Cell Transplantation $212201-2214$. (https://doi.org/10.3727/09636891 1X637362)

Meisel R, Zibert A, Laryea M, Gobel U, Daubener W \& Dilloo D 2004 Human bone marrow stromal cells inhibit allogeneic T-cell responses by indoleamine 2,3-dioxygenase-mediated tryptophan degradation. Blood 103 4619-4621. (https://doi.org/10.1182/blood-2003-11-3909)

Moore KW, A O'Garra, R de Waal Malefyt, Vieira P \& Mosmann TR 1993 Interleukin-10. Annual Review of Immunology 11 165-190. (https://doi. org/10.1146/annurev.iy.11.040193.001121)

Najar M, Raicevic G, Boufker HI, Fayyad Kazan H, De Bruyn C, Meuleman N, Bron D, Toungouz M \& Lagneaux L 2010 Mesenchymal stromal cells use PGE2 to modulate activation and proliferation of lymphocyte subsets: combined comparison of adipose tissue, Wharton's Jelly and bone marrow sources. Cellular Immunology 264 171-179. (https://doi.org/10.1016/j.cellimm.2010.06.006)

O'Farrell AM, Liu Y, Moore KW \& Mui AL 1998 IL-10 inhibits macrophage activation and proliferation by distinct signaling mechanisms: evidence for Stat3-dependent and -independent pathways. EMBO Journal 17 1006-1018.

Phinney DG \& Prockop DJ 2007 Concise review: mesenchymal stem/ multipotent stromal cells: the state of transdifferentiation and modes of tissue repair - current views. Stem Cells 25 2896-2902. (https://doi. org/10.1634/stemcells.2007-0637)

Rajaraman G, White J, Tan KS, Ulrich D, Rosamilia A, Werkmeister J \& Gargett CE 2013 Optimization and scale-up culture of human endometrial multipotent mesenchymal stromal cells: potential for clinical application. Tissue Engineering Part C: Methods 19 80-92. (https://doi.org/10.1089/ten.tec.2011.0718)

Roederer M 2011 Interpretation of cellular proliferation data: avoid the panglossian. Cytometry A 79 95-101. (https://doi.org/10.1002/ cyto.a.21010)

Rohart F, Mason EA, Matigian N, Mosbergen R, Korn O, Chen T, Butcher S, Patel J, Atkinson K, Khosrotehrani K et al. 2016 A molecular classification of human mesenchymal stromal cells. Peer/ 4 e1845. (https://doi.org/10.7717/peerj.1845)

Schindelin J, Arganda-Carreras I, Frise E, Kaynig V, Longair M, Pietzsch T, Preibisch S, Rueden C, Saalfeld S, Schmid B et al. 2012 Fiji: an opensource platform for biological-image analysis. Nature Methods $\mathbf{9}$ 676-682. (https://doi.org/10.1038/nmeth.2019)

Schmidt A, Oberle N \& Krammer PH 2012 Molecular mechanisms of tregmediated T cell suppression. Frontiers in Immunology 351.

Schwab KE \& Gargett CE 2007 Co-expression of two perivascular cell markers isolates mesenchymal stem-like cells from human endometrium. Human Reproduction 22 2903-2911. (https://doi.org/10.1093/humrep/dem265)

Sivanathan KN, Rojas-Canales DM, Hope CM, Krishnan R, Carroll RP, Gronthos S, Grey ST \& Coates PT 2015 Interleukin-17A-induced human mesenchymal stem cells are superior modulators of immunological function. Stem Cells 33 2850-2863. (https://doi.org/10.1002/stem.2075)

Sivasubramaniyan K, Harichandan A, Schumann S, Sobiesiak M, Lengerke C, Maurer A, Kalbacher H \& Buhring HJ 2013 Prospective isolation of mesenchymal stem cells from human bone marrow using novel antibodies directed against Sushi domain containing 2. Stem Cells and Development 22 1944-1954. (https://doi.org/10.1089/ scd.2012.0584)

Soleymaninejadian E, Pramanik K \& Samadian E 2012 Immunomodulatory properties of mesenchymal stem cells: cytokines and factors. American Journal of Reproductive Immunology 67 1-8. (https://doi.org/10.1111/ j.1600-0897.2011.01069.x)

Su WR, Zhang QZ, Shi SH, Nguyen AL \& Le AD 2011 Human gingivaderived mesenchymal stromal cells attenuate contact hypersensitivity via prostaglandin E2-dependent mechanisms. Stem Cells 29 1849-1860. (https://doi.org/10.1002/stem.738)

Sun Z, Han Q, Zhu Y, Li Z, Chen B, Liao L, Bian C, Li J, Shao C \& Zhao RC 2011 NANOG has a role in mesenchymal stem cells' immunomodulatory effect. Stem Cells and Development 20 1521-1528. (https://doi.org/10.1089/scd.2010.0366)

Ulrich D, Muralitharan R \& Gargett CE 2013 Toward the use of endometrial and menstrual blood mesenchymal stem cells for cell-based therapies. Expert Opinion on Biological Therapy 13 1387-1400. (https://doi.org/10 .1517/14712598.2013.826187)

Ulrich D, Edwards SL, Su K, Tan KS, White JF, Ramshaw JA, Lo C, Rosamilia A, Werkmeister JA \& Gargett CE 2014 Human endometrial mesenchymal stem cells modulate the tissue response and mechanical behavior of polyamide mesh implants for pelvic organ prolapse repair. Tissue Engineering Part A 20 785-798.

Yang SH, Park MJ, Yoon IH, Kim SY, Hong SH, Shin JY, Nam HY, Kim YH, Kim B \& Park CG 2009 Soluble mediators from mesenchymal stem cells suppress $\mathrm{T}$ cell proliferation by inducing IL-10. Experimental and Molecular Medicine 41 315-324. (https://doi.org/10.3858/ emm.2009.41.5.035)

Zafranskaya M, Nizheharodava D, Yurkevich M, Ivanchik G, Demidchik Y, Kozhukh H \& Fedulov A 2013 PGE2 contributes to in vitro MSC-mediated inhibition of non-specific and antigen-specific T cell proliferation in MS patients. Scandinavian Journal of Immunology 78 455-462. (https://doi. org/10.1111/sji.12102)

Zhang B, Liu R, Shi D, Liu X, Chen Y, Dou X, Zhu X, Lu C, Liang W, Liao L et al. 2009 Mesenchymal stem cells induce mature dendritic cells into a novel Jagged-2-dependent regulatory dendritic cell population. Blood 113 46-57. (https://doi.org/10.1182/blood-2008-04-154138)

Received 24 May 2018

First decision 4 July 2018

Revised manuscript received 11 October 2018

Accepted 25 October 2018 